\title{
Effects of an artisanal fishery on non-spawning grouper populations
}

\author{
Philip P. Molloy ${ }^{1, *}$, John D. Reynolds ${ }^{1}$, Matthew J. G. Gage ${ }^{2}$, Isabelle M. Côté ${ }^{1}$ \\ ${ }^{1}$ Department of Biological Sciences, Simon Fraser University, 8888 University Drive, Burnaby, British Columbia V5A 1S6, \\ Canada \\ ${ }^{2}$ Centre for Ecology, Evolution and Conservation, School of Biological Sciences, University of East Anglia, Norwich, \\ Norfolk NR4 7TJ, UK
}

\begin{abstract}
Many populations of groupers (Teleostei: Serranidae) are overfished, partly because most species form spawning aggregations that are temporally and spatially predictable and therefore easily targeted by fisheries. However, most grouper fisheries operate year-round, thus there can also be high mortality during non-spawning periods. We investigated the impact of fishing around Anguilla, British West Indies, on a commercially important grouper, the red hind Epinephelus guttatus, during the non-breeding season. We combined information on the spatial intensity of the fishery with underwater surveys of groupers to test for associations between fishing intensity and fish size and density across 19 sites. Red hind density was unrelated to fishing intensity but red hinds were larger in areas that were targeted more intensively by fishers. While these results might be taken to suggest that fishing has no negative impacts on red hind demographics, we present evidence from fish markets that fishing intensity on this species during the non-spawning season is high. A variety of mechanisms may mask site-specific negative impacts on density and size of red hinds. In particular, fishers can easily move among sites to track grouper abundance and body size, thereby making it difficult to detect impacts on red hinds during the non-spawning season.
\end{abstract}

KEY WORDS: Caribbean · Coral reef · Grouper · Overexploitation · Serranid · Spawning aggregation · Subsistence fishery

Resale or republication not permitted without written consent of the publisher

\section{INTRODUCTION}

Overexploitation of coral reef resources is a widespread, long-standing problem, particularly in the Caribbean (Jackson 1997, Jackson et al. 2001, Hawkins \& Roberts 2004, Precht \& Aronson 2006). A common consequence of overfishing is the reduction in abundance of large predatory fish in particular (Pauly et al. 2001, Christensen et al. 2003). Groupers (Serranidae) provide a prime example, with diminishing stocks being widely reported (e.g. Coleman et al. 1999, Huntsman et al. 1999, Sala et al. 2001). For example, the number of Nassau grouper Epinephelus striatus spawning aggregations in the Caribbean has declined by $>80 \%$ over the past $30 \mathrm{yr}$ (Sala et al. 2001). Fishing also reduces the diversity and size of species (Chiappone et al. 2000, Dulvy et al. 2004).
Many groupers exhibit 2 features that may make them particularly vulnerable to exploitation: femaleto-male sex change and spawning in aggregations. It has been hypothesised that female-first sex-changers may be particularly prone to overfishing because of the size-selectivity of fishing. In female-to-male sexchangers, males are larger than females on average. Thus, size-selective fisheries tend to disproportionately kill males, potentially leaving insufficient numbers to fertilise all females (Bannerot et al. 1987, Huntsman \& Schaaf 1994, Vincent \& Sadovy 1998, Côté 2003, Alonzo \& Mangel 2004). In addition, when groupers spawn in spatially and temporally predictable aggregations they become easy targets for fishers (Coleman et al. 1996, Arreguín-Sánchez \& Pitcher 1999, Domeier et al. 2002, Sadovy \& Domeier 2005). These concerns have led to considerable effort 
to document the effects of fishing on sex ratios, reproductive potential, and sizes of groupers at spawning aggregations (e.g. Shapiro et al. 1993, Sadovy et al. 1994, Beets \& Friedlander 1999, Nemeth 2005, Sadovy \& Domeier 2005, Nemeth et al. 2007).

By comparison, less attention has been given to the impacts of fishing during the non-spawning season, yet these effects may also have far-reaching impacts on grouper populations. While spawning aggregations form for up to 4 mo each year (Domeier \& Colin 1997, Claydon 2004), many fisheries operate year-round, and a substantial portion of fishing mortality on groupers occurs during the non-breeding season. In addition, newly mature individuals may find spawning aggregations by following experienced individuals from their non-spawning habitats (Bolden 2000). If size-selective fishing removes these larger, experienced individuals, migration to spawning sites by first-time breeders may be impaired. Furthermore, any size-selective fishing in non-spawning areas may exacerbate impacts on sex ratios, population sizes and body size caused by sizeselective fishing on spawning aggregations (McGovern et al. 2002). The effects of fishing during nonspawning periods could therefore be important in relation to both conservation and fisheries management (Ehrhardt \& Deleveaux 2007). Assessments of grouper stocks usually include effects of fishing on non-spawning populations (e.g. Arreguín-Sánchez \& Pitcher 1999, Ehrhardt \& Deleveaux 2007); however, these assessments are rarely published in the primary literature (Ehrhardt \& Deleveaux 2007), are often plagued by poor data availability (e.g. Porch et al. 2006, Ehrhardt \& Deleveaux 2007) and rely on fisheries catch data (Ault et al. 2005).

In the present paper, we investigate the effects of fishing on non-spawning red hind Epinephelus guttatus populations around Anguilla, British West Indies. The red hind is an ecologically and commercially important grouper (Heemstra \& Randall 1993, Coleman et al. 2000). Red hinds make up a large proportion of recreational and fisheries catches throughout the Caribbean (Burnett-Herkes 1975, Heemstra \& Randall 1993). Although there are no data on the exact contribution of red hinds to the Anguillian artisanal fishery, anecdotal observations suggest that they are an important component of the reef-fish catch (comprising approximately one-third of the catch; S. Wynne, Deputy Director, Department of Fisheries and Marine Resources, Anguilla, pers. comm.; P. P. Molloy pers. obs.). We quantify the relationships between fishing effort and 2 red hind demographic parameters: density and body size, and consider the implications for detecting impacts of potentially mobile fishers on populations during the non-spawning season.

\section{MATERIALS AND METHODS}

Study species and study site. Red hinds are a medium-sized $(76 \mathrm{~cm}$ maximum total length [TL]; Froese \& Pauly 2009) grouper (Teleostei: Serranidae) found throughout the tropical western Atlantic. They exhibit female-to-male sex change, which occurs at approximately 20 to $30 \mathrm{~cm}$ TL (Sadovy et al. 1994). Reproduction takes place in large aggregations around full moons from December to February (Colin et al. 1987, Beets \& Friedlander 1999, Nemeth et al. 2007). During the non-spawning season, red hinds favour shallow (<100 m depth), low-relief (Sluka et al. 1996), patchy coral and rocky reefs (Burnett-Herkes 1975, Heemstra \& Randall 1993) containing caves or crevices (in which they often seek shelter) and bordered by sand patches (Burnett-Herkes 1975).

Fieldwork was conducted on reefs around Anguilla $\left(18^{\circ} 15^{\prime} \mathrm{N}, 63^{\circ} 10^{\prime} \mathrm{W}\right.$; Fig. 1) in July and August 2003, and May to June 2004. Anguilla is a small $\left(\sim 100 \mathrm{~km}^{2}\right)$ low-lying island in the northeastern Caribbean. Its marine habitats consist primarily of seagrass and reefs dominated by algae, soft coral and sponges. Fringing reefs are dotted along parts of the northwestern coast, which features protected bays, cliffs, beaches and

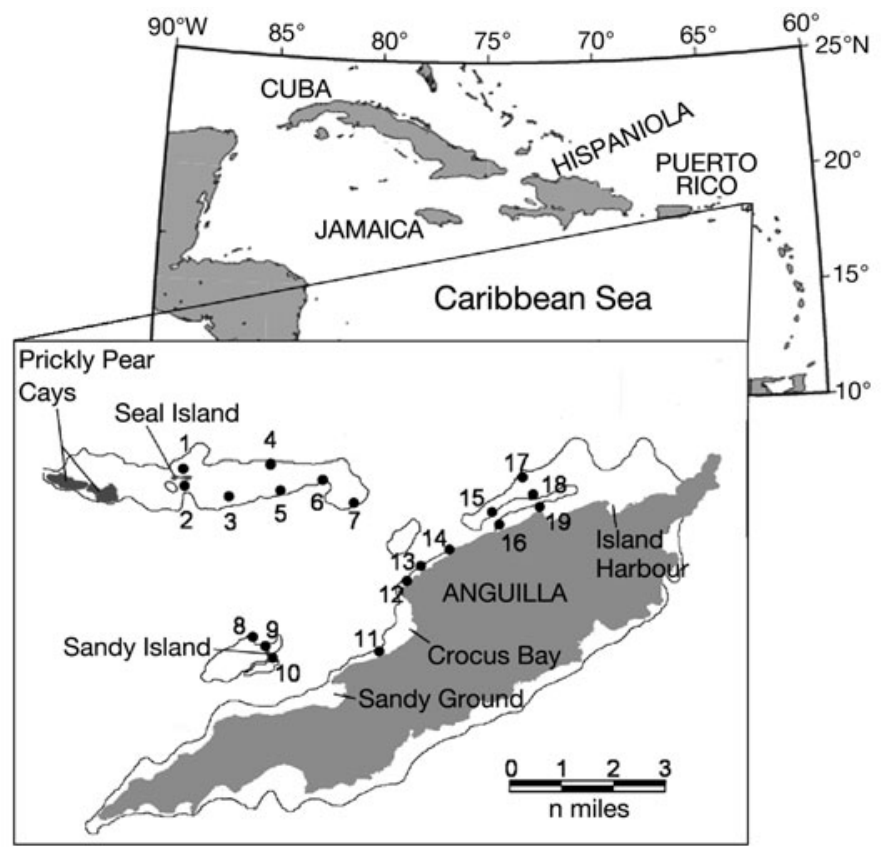

Fig. 1. Location of Anguilla in the Caribbean Sea and the position of the 19 study sites around Anguilla. $1=$ Seal Island North $1 ; 2=$ Seal Island South $3=$ The Reef $1 ; 4=$ Seal Island North $2 ; 5=$ The Reef $2 ; 6=$ The Reef $3 ; 7=$ The Reef East $; 8=$ Tom Dowling $; 9=$ Sandy Island North $; 10=$ Sandy Island South; 11 = North Cliffs; 12 = Limestone Bay; $13=$ Black Garden; $14=$ Frenchman; $15=$ Madeirman Southwest; $16=$ Fountain Beach; 17 = Madeirman North; 18 = Madeirman South; $19=$ Shoal Bay Reef. Figure developed using maptool (www.seaturtle.org/maptool) 
rocky shore. Further offshore is a barrier reef that has a high-relief, exposed north side, which protects the shallower, leeward side. Between the fringing and barrier reefs are large expanses of sand and seagrass.

Just as for many small-scale artisanal fisheries, very few data are available on the fisheries or fish stocks around Anguilla. Murray et al. (2001), Abernethy (2005) and Abernethy et al. (2007) provide descriptions of the fisheries, but quantitative data on speciesspecific catches of the different fisheries do not exist. The Anguillian commercial fisheries target inshore reef fishes-predominantly groupers (Serranidae), surgeonfishes (Acanthuridae), parrotfishes (Scaridae) and grunts (Haemulidae), shallow-shelf fishes (mainly yellowtail snapper Ocyurus chrysurus), spiny lobster Panulirus argus, and spotted spiny lobster P. guttatus (Murray et al. 2001, Abernethy et al. 2007). At the time of the present study, there were approximately 130 open-deck fishing boats (up to $10 \mathrm{~m}$ long, with up to twin $250 \mathrm{hp}$ outboard motors) in Anguilla's harbours. However, many of these boats were owned by fishers who do not fish intensively for recreation, subsistence or commercial gains (Abernethy 2005).

Trap fishing is the main form of fishing on inshore reefs (Mahon \& Hunte 2001, Abernethy 2005). Traps are made of galvanised wire around a wooden or metal frame (Murray et al. 2001) with an entrance funnel ( $\sim 25 \mathrm{~cm}$ long and $15 \mathrm{~cm}$ wide; S. Wynne pers. comm.). Mesh sizes on traps are legally restricted to 1.5 inches (3.8 cm) (Government of Anguilla 2000) and compliance is good (S. Wynne pers. comm.; P. P. Molloy pers. obs.). Inshore-reef fishers usually set between 30 and 50 traps, which are soaked for between $6 \mathrm{~h}$ and several days and baited with goat's hide, when targeting groupers.

In addition to being caught in fish traps, Anguillian red hinds are also caught by recreational hook-andlining and spearfishing, as well as bycatch in spottedspiny-lobster traps. Although relative catch rates of red hinds in these fisheries do not exist, anecdotal observations at the time of the present study suggested that the inshore trap fishery accounted for the majority of red hind catches (P. P. Molloy pers. obs.). We therefore focus on this fishery, which is carried out for both recreational and commercial purposes. Measurements of trapped fish at the island's largest fish market indicated that red hinds of over $22.5 \mathrm{~cm}$ standard length (SL) are caught in traps.

Reef fish abundance and red hind demographics. Nineteen reef sites were selected based on accessibility (Fig. 1). Sites that were not separated by large areas of sand, which red hinds do not inhabit, were more than $400 \mathrm{~m}$ from any neighbouring site(s). This distance exceeds published home-range sizes of nonspawning red hinds (Shapiro et al. 1994), and hence the potential for inter-site mixing during the sampling period was low. Habitat and fish surveys were carried out at depths of 5 and $10 \mathrm{~m}$ to match trapping depths at these sites (i.e. 3 to $13 \mathrm{~m}$ ). The survey depths fall within the known depth range for red hinds and are comparable to those surveyed in previous studies of inshore red hind populations (Burnett-Herkes 1975, Shapiro et al. 1994, Sluka et al. 1996). Inshore reefs in Anguilla rarely occur much deeper. At 3 sites (The Reef 3, North Cliffs and Madeirman South West; Fig. 1), surveys could only be conducted at a depth of $5 \mathrm{~m}$ because reefs did not extend to $10 \mathrm{~m}$ depth.

At each site and depth, the density of all fish species, including red hinds, was recorded by a diver swimming along haphazardly located $30 \mathrm{~m} \times 6 \mathrm{~m}$ transects at approximately $3 \mathrm{~m} \mathrm{~min} \mathrm{~m}^{-1}$. Sample sizes differed between sites and years according to accessibility and presence of reef at $10 \mathrm{~m}$ depth; total sample sizes ranged from 5 to 22 transects site $^{-1}$ (Table 1). All crevices and overhangs within each transect were carefully searched. Fish density data were collected in both years at The Reef 1, Limestone Bay, Black Garden, Frenchman and Shoal Bay Reef but only in 2004 at the other sites (Table 1). Red hind densities were averaged for each site across the 2 depths within years.

The TLs of all red hinds encountered along transects in 2004 (but not 2003) were estimated visually to the nearest $\mathrm{cm}$. Observers were trained beforehand to estimate length underwater using fish outlines and PVC pipes ranging in size from 8 to $50 \mathrm{~cm}$ (sensu Bell et al. 1985, Friedlander \& Parrish 1998, Dulvy et al. 2004). To examine variation in accuracy of size estimates between days, the length of 20 randomly selected pipes were estimated each day. Estimated and actual pipe lengths were highly correlated $(\mathrm{r}=0.98 \mathrm{p}<$ $0.0001, \mathrm{n}=562$ ) and the accuracy of our measurements was similar among days (Kruskal-Wallis test, $\chi_{28}^{2}=$ 39.7, $\mathrm{p}=0.07$ ). Estimates of red hind length could not be obtained at $10 \mathrm{~m}$ for The Reef 1 since no red hinds were observed on the single transect we were able to perform at this site and depth in 2004. Where possible, estimates of red hind size were averaged across depths for each site.

Habitat assessment. Habitat characteristics (Table 2) were measured at each site and depth to control for any confounding effects of habitat on red hind demography. Habitat data were collected using 10 haphazardly placed $1 \mathrm{~m}^{2}$ quadrats at each depth at each site. We measured characteristics that were found to be important in previous investigations of grouper habitat preferences (Burnett-Herkes 1975, Nagelkerken 1979, 1982, Sullivan \& Sluka 1996, Sluka et al. 2001), which can be broadly placed into the following 4 categories. (1) Reef patchiness (Burnett-Herkes 1975, Shapiro et al. 1994) was measured as the heterogeneity in hard 
Table 1. Summary statistics for red hind (RH) demographics and fishing estimates at 19 sites around Anguilla. RH demographic variables are mean \pm SD of density and body sizes; fishing estimates are our observational rank (Obs. rank), mean \pm SD fisher ranks, distance to nearest port, total distance to all ports, number of boats in the nearest port and scores for the composite PCA fishing factor (see 'Materials and methods' for details). Negative PCA scores are presented so that high scores indicate high fishing intensity. Site numbers correspond to Fig. 1. Number of fish-census transects (N) performed at depths of 5 and $10 \mathrm{~m}$ in 2003, 2004 and in total $(\Sigma)$ are given. Red hind densities are based on surveys done in both years; size estimates were only performed in 2004. $\mathrm{n}$ miles $=$ nautical miles; TL $=$ total length

\begin{tabular}{|c|c|c|c|c|c|c|c|c|c|c|c|}
\hline Site & $2003^{5}$ & $\begin{array}{l}\mathrm{N} \\
\mathrm{m} / 10 \mathrm{r} \\
2004\end{array}$ & $\mathrm{n}$ & $\begin{array}{c}\text { Mean RH } \\
\text { density } \\
\text { (no. per } 180 \mathrm{~m}^{2} \text { ) }\end{array}$ & $\begin{array}{l}\text { Mean RH } \\
\text { size } \\
(\mathrm{cm}, \mathrm{TL})\end{array}$ & $\begin{array}{l}\text { Obs. } \\
\text { rank }\end{array}$ & $\begin{array}{l}\text { Mean fisher } \\
\text { rank }\end{array}$ & $\begin{array}{l}\text { Dist. to } \\
\text { nearest port } \\
\text { (n miles) }\end{array}$ & $\begin{array}{l}\text { Total dist. } \\
\text { to all } \\
\text { ports } \\
\text { (n miles) }\end{array}$ & $\begin{array}{c}\text { No. of } \\
\text { boats in } \\
\text { nearest } \\
\text { port }\end{array}$ & $\begin{array}{l}\text { PCA } \\
\text { fishing } \\
\text { factor }\end{array}$ \\
\hline 1. Seal Island North 1 & $5 / 5$ & $5 / 5$ & 20 & $0.10 \pm 0.32$ & $23.00^{\mathrm{a}}$ & 6 & $6.67 \pm 2.24$ & 5.64 & 21.00 & 29 & 2.54 \\
\hline 2. Seal Island South & $5 / 5$ & $5 / 5$ & 20 & $0.20 \pm 0.63$ & $40.50 \pm 14.85$ & 10 & $8.11 \pm 2.62$ & 5.14 & 19.42 & 29 & 3.28 \\
\hline 3. The Reef 1 & $1 / 4$ & $5 / 1$ & 11 & $1.09 \pm 1.30$ & $30.20 \pm 11.84$ & 10 & $8.44 \pm 2.07$ & 3.36 & 13.85 & 5 & 1.75 \\
\hline 4. Seal Island North 2 & $0 / 0$ & $5 / 5$ & 10 & $0.50 \pm 0.71$ & $35.40 \pm 5.13$ & 5 & $7.44 \pm 1.59$ & 3.97 & 15.67 & 5 & 1.05 \\
\hline 5. The Reef 2 & $0 / 0$ & $5 / 5$ & 10 & $2.20 \pm 1.32$ & $26.77 \pm 6.77$ & 10 & $8.78 \pm 2.17$ & 3.65 & 14.68 & 5 & 2.12 \\
\hline 6. The Reef 3 & $0 / 0$ & $5 / 0$ & 5 & $1.20 \pm 0.84$ & $25.83 \pm 6.43$ & 9 & $8.44 \pm 2.35$ & 4.07 & 15.67 & 5 & 2.16 \\
\hline 7. The Reef East & $0 / 0$ & $5 / 5$ & 10 & $0.50 \pm 0.71$ & $30.40 \pm 6.84$ & 6 & $8.22 \pm 3.27$ & 2.97 & 12.76 & 5 & 0.60 \\
\hline 8. Tom Dowling & $0 / 0$ & $5 / 5$ & 10 & $0.20 \pm 0.42$ & $21.50 \pm 0.71$ & 5 & $5.22 \pm 2.05$ & 2.08 & 13.19 & 29 & -0.86 \\
\hline 9. Sandy Island North & $0 / 0$ & $5 / 5$ & 10 & $0.80 \pm 1.14$ & $19.89 \pm 4.34$ & 6 & $5.44 \pm 2.01$ & 1.88 & 12.71 & 29 & -0.77 \\
\hline 10. Sandy Island South & $0 / 0$ & $5 / 5$ & 10 & $0.60 \pm 0.97$ & $27.50 \pm 6.28$ & 7 & $4.67 \pm 1.87$ & 1.57 & 12.00 & 29 & -1.08 \\
\hline 11. North Cliffs & $0 / 0$ & $5 / 0$ & 5 & $1.00 \pm 0.71$ & $24.40 \pm 3.05$ & 2 & $4.22 \pm 1.20$ & 1.07 & 8.75 & 5 & -2.88 \\
\hline 12. Limestone Bay & $7 / 5$ & $5 / 5$ & 22 & $0.32 \pm 0.72$ & $15.50 \pm 0.71$ & 7 & $3.78 \pm 1.86$ & 1.13 & 8.63 & 5 & -2.10 \\
\hline 13. Black Garden & $5 / 5$ & $5 / 5$ & 20 & $0.70 \pm 0.80$ & $22.89 \pm 4.20$ & 1 & $3.78 \pm 1.99$ & 1.42 & 9.13 & 5 & -3.00 \\
\hline 14. Frenchman & $5 / 5$ & $5 / 5$ & 20 & $0.45 \pm 0.69$ & $29.50 \pm 9.19$ & 6 & $5.33 \pm 3.08$ & 2.22 & 9.92 & 5 & -1.11 \\
\hline 15. Madeirman South & $0 / 0$ & $5 / 5$ & 10 & $1.10 \pm 1.45$ & $23.00 \pm 7.06$ & 8 & $6.78 \pm 2.49$ & 1.97 & 11.83 & 24 & -0.07 \\
\hline 16. Fountain Beach & $0 / 0$ & $5 / 5$ & 10 & $0.10 \pm 0.32$ & $15.00^{\mathrm{a}}$ & 7 & $5.67 \pm 2.74$ & 2.58 & 10.93 & 24 & -0.05 \\
\hline 17. Madeirman North & $0 / 0$ & $5 / 5$ & 10 & $1.00 \pm 1.33$ & $29.29 \pm 8.64$ & 6 & $6.89 \pm 1.62$ & 2.08 & 12.03 & 24 & -0.32 \\
\hline $\begin{array}{l}\text { 18. Madeirman South } \\
\text { West }\end{array}$ & $0 / 0$ & $9 / 0$ & 9 & $1.11 \pm 1.17$ & $27.20 \pm 6.48$ & 7 & $6.44 \pm 2.46$ & 2.40 & 11.11 & 24 & -0.29 \\
\hline 19. Shoal Bay Reef & $5 / 5$ & $5 / 5$ & 20 & $0.30 \pm 0.47$ & $16.57 \pm 6.85$ & 7 & $6.33 \pm 2.65$ & 1.68 & 11.78 & 24 & -0.53 \\
\hline
\end{tabular}

Table 2. Results of comparisons of habitat characteristics at 5 and $10 \mathrm{~m}$ depth. Depths were paired within site and compared with paired $t$-tests; negative $t$-values indicate higher estimates at $5 \mathrm{~m}$ than $10 \mathrm{~m}$ depth on average. No differences remained significant after controlling for false discovery rate. $\mathrm{df}=15$ for all tests

\begin{tabular}{|c|c|c|c|c|}
\hline Habitat characteristic & Variable & Transformation & Paired $t$ & $\mathrm{p}$ \\
\hline Biotic patchiness & Coefficient of variation in \% hard coral cover & $\log _{10}$ & -1.95 & 0.07 \\
\hline \multirow[t]{4}{*}{ Abiotic substratum } & Proportion of fine sand & Arcsin-square root & -1.26 & 0.23 \\
\hline & Proportion of coarse sand & Arcsin-square root & 1.94 & 0.07 \\
\hline & Proportion of rubble & Arcsin-square root & 1.11 & 0.29 \\
\hline & Proportion of hard substratum & Arcsin-square root & 0.47 & 0.66 \\
\hline \multirow[t]{3}{*}{ Physical heterogeneity } & Rugosity & None & 2.48 & 0.03 \\
\hline & Crevice index & None & 0.27 & 0.79 \\
\hline & Relief & Square root & 2.92 & 0.01 \\
\hline \multirow[t]{2}{*}{ Reef health } & Percent hard coral cover & $\log _{10}$ & 2.72 & 0.01 \\
\hline & Fish diversity index & $\log _{10}$ & -2.29 & 0.04 \\
\hline
\end{tabular}

coral cover, which we calculated for each depth and site as the coefficient of variation in percent hard coral cover $\mathrm{m}^{-2}$. (2) Abiotic substratum (Sluka et al. 1996) was divided into 4 types: fine sand (grains smaller than ca. $1 \mathrm{~mm}$ diameter), coarse sand (grains between ca. $1 \mathrm{~mm}$ and $10 \mathrm{~mm}$ diameter), rubble (pieces of broken debris between 10 and $100 \mathrm{~mm}$ diameter in any dimension), and hard substratum (i.e. dead hard coral, or bedrock). The percent cover of each substratum type in each quadrat was estimated visually. (3) Physical heterogeneity was measured in 3 ways. First, relief was measured by calculating the difference in depth between the shallowest and deepest side of each quadrat. High relief indicates a steeply sloping reef face. Second, rugosity was measured at 10 random locations per site and depth (total $\mathrm{N}=350$ since 3 sites were not surveyed at $10 \mathrm{~m}$ depth). A $280 \mathrm{~cm}$ fine-link chain was draped across the irregularities of the sub- 
stratum in a line perpendicular to the reef slope and the horizontal straight-line distance between the ends of the chain was measured. Rugosity was then calculated by dividing chain length $(280 \mathrm{~cm})$ by the straightline distance, and averaging across the 10 replicates within a depth at a site. Flat terrain would have a rugosity value of 1 ; highly complex habitat would have higher values, to a maximum of 280 (English et al. 1997). Third, the depth of each crevice within each quadrat was measured using a measuring stick and the values were summed to obtain the total crevice depth in the $1 \mathrm{~m}^{2}$ quadrat. (4) Reef health was assessed in 2 ways. Percent cover of living hard coral was estimated visually in each quadrat, and fish species diversity (derived from the fish abundance transects described above) was summarised using the Shannon-Wiener index (Begon et al. 1996).

Fishing effort. Fishing effort was approximated using 5 metrics. (1) Each site was ranked from 1 to 10 (1 = lightly fished; 10 = heavily fished) based on personal observations of traps or fishing boats with traps at each site (henceforth, 'observational rank'). This measure captures in situ fishing effort, albeit less accurately than repeated, site-specific estimates of trapping rates, which could not be collected owing to time and logistical constraints. (2) Six fishers and 3 current or retired employees of the Anguillian Department of Fisheries and Marine Resources (DFMR) were asked to rate fishing effort at each site on a scale from 0 (not fished) to 10 (heavily fished). The ranking was based on their opinion of the extent to which each site was used by all inshore-reef trap fishers, regardless of their target (i.e. fish or spotted spiny lobster, which take fish bycatch). No weighting was applied to the different fisheries because there is no catch information available to do so meaningfully. An average rank was calculated for each site to give a continuous variable, termed 'mean fisher rank'. (3) In Anguilla as in other small-scale artisanal fisheries, sites far from ports are more costly to visit, in terms of fuel (Defeo \& Castilla 1998, Cabrera \& Defeo 2001, Rueda \& Defeo 2003, Abernethy et al. 2007); additionally, sites near ports in Anguilla tend to be more sheltered during the hurricane season, and thus, are more likely to be fished year-round. We therefore measured the shortest navigable distance (nautical miles) from each site to the nearest main fishing ports (Sandy Ground, Crocus Bay or Island Harbour; Fig. 1). (4) Because fishers from all ports have legal access to all sites, we also summed the distance of each site to all 3 ports. (5) Finally, we assumed that sites closer to larger ports may be more intensely fished, and hence counted the number of fishing boats in the port nearest to each site.

The relationships between red hind demographics and each fishing effort metric were examined; how- ever, several of the fishing effort variables were highly correlated (see 'Results'). To reduce this multicollinearity and develop a single metric of fishing effort, we used a principal component analysis (PCA). The first PCA factor captured $73.6 \%$ of the variation in the data, and 4 fishing metrics loaded negatively onto this factor (observational rank: -0.429 ; mean fisher rank: -0.514 ; distance to nearest port: -0.534 ; sum distance to all ports: -0.517$)$. The number of boats in the nearest port did not load highly onto this factor; therefore, we excluded this index from the PCA and considered it in our analyses only in its raw form. For ease of interpretation, we therefore used the negative of this composite fishing factor in tests of relationships between red hind demographics and fishing effort.

Statistical analyses. We controlled for false discovery rate (FDR, i.e. the proportion of falsely rejected null hypotheses) in all multiple analyses (Benjamini \& Hochberg 1995). We set the acceptable FDR at 0.05. Control of FDR was selected in preference to Bonferroni-type procedures because it is less restrictive and more powerful during exploratory analyses (Garciá 2004).

Data were screened for outliers and normality of distributions, and the necessary transformations were performed (Table 2). All percentage cover variables were converted to proportions and arcsine-square root-transformed, except percent coral cover, which was more effectively normalised with a $\log _{10}$ transformation (Table 2).

Non-parametric tests were used to examine differences between years in the density of red hinds at sites that were surveyed in both years and among sites in the density and size of red hinds. Non-parametric tests were used because data were highly skewed and sample sizes differed between groups. Density data were averaged across years for subsequent analyses. However, because there were marginally non-significant differences between years in red hind densities at Shoal Bay Reef and The Reef 1 (see 'Results'), we repeated all tests using only density data from 2004 at those 2 sites. Doing so did not change our conclusions, so we do not report these results. Paired $t$-tests were used to compare habitat features at different depths within site (Table 2). When there was no significant difference between depths (after controlling for false discovery rate), values were averaged across depths. When differences existed, data for different depths were treated as separate variables. Many of these variables were too weakly correlated with one another to be effectively condensed by PCA. Since none of the habitat variables was correlated with any red hind demographic parameters (see 'Results'), we did not control for their effects before investigating the impact of fishing. 
Pearson's correlation was used to test for relationships among each of the 5 metrics of fishing effort as well as the principal component factor that combined the effort variables. A Wilcoxon's paired sign-rank test was used to test whether fishers rated sites differently from employees of the DFMR. Finally, Pearson's correlations were used to test for relationships between the fishing metrics and red hind size and density.

All analyses were performed using R (R Development Core Team 2009).
Table 3. Relationships among indices of fishing. $\mathrm{r}$ is the Pearson's correlation coefficient and $\mathrm{p}$ is the associated significance; $\mathrm{N}=19$ for all tests. ${ }^{*}$ Relationships that remained significant after controlling for false discovery rate

\begin{tabular}{|lcc|}
\hline Test & $\mathrm{r}$ & $\mathrm{p}$ \\
\hline Mean fisher rank vs. observational rank & 0.70 & $<0.001^{*}$ \\
Mean fisher rank vs. distance to nearest port & 0.73 & $<0.001^{*}$ \\
Mean fisher rank vs. summed distance to all ports & 0.65 & $0.002^{*}$ \\
Observational rank vs. distance to nearest port & 0.48 & 0.036 \\
Observational rank vs. summed distance to all ports & 0.46 & 0.047 \\
Distance to nearest port vs. summed distance to all ports & 0.94 & $<0.001^{*}$ \\
Number of boats. All correlations & -0.10 to $0.30>0.20$ \\
\hline
\end{tabular}

\section{RESULTS}

\section{Temporal and spatial variation in red hind populations}

There were no significant differences in red hind densities between the 2 years when sites were tested independently (all Wilcoxon unpaired $W>47$, all $\mathrm{p}>$ 0.05; FDR-adjusted $\mathrm{p}>0.22$ ). Red hind density and body size varied significantly among sites (density: Kruskal-Wallis $\chi^{2}{ }_{18}=47.03, \mathrm{p}<0.001$; size: KruskalWallis $\chi_{18}^{2}=46.49, \mathrm{p}<0.001$; Table 2). Red hind density and body size were not correlated across sites (Spearman's $\mathrm{r}=0.24, \mathrm{p}=0.33, \mathrm{n}=19$ ).

\section{Habitat variation and red hind populations}

There were no significant relationships between any habitat variable and red hind density or size (density: in all cases, $-0.37<\mathrm{r}>0.33$, $\mathrm{p}>0.11$; size: in all cases, $-0.32<\mathrm{r}>0.31, \mathrm{p}>0.18)$

\section{Fishing intensity and red hind populations}

All sites were fished to some extent (Table 1). There was a significant difference in mean fisher rank among sites (Kruskal-Wallis $\chi^{2}{ }_{8}=25.14, \mathrm{p}=0.001$ ). Interviewed fishers did not differ from employees of DFMR in their ratings of fishing effort at each site (Wilcoxon paired $W=136, \mathrm{p}=0.25$ ). Many of the indices of fishing intensity were correlated with one another, with the exception of the number of boats in the nearest port (Table 3). Our observational rank (median $=7$, interquartile range $=1.5$ ) was highly positively correlated to mean fisher rank (median $=6.4$, interquartile range $=2.5$; Table 3 ), indicating that the fishing activities we observed agreed with fishers' perceptions of site-specific use by local fishers. Contrary to a priori expectation, but in keeping with our observations of fishing activities, sites that were further from port were ranked by fishers as the most heavily targeted (Table 3).

Despite wide variation among the 19 sites in fishing intensity, red hind densities were not significantly related to any measure of fishing effort (Table $4 a$, Fig. 2). Red hind size was positively related to mean fisher rank, distance to nearest port and the PCA fishing factor (Table 4b, Fig. 3). Red hind size tended to increase with summed distance to all ports, but this was not significant after controlling for FDR (Table 4b). Neither red hind density nor size was related to the number of fishing boats in the nearest port (Table 4).

Table 4. Relationships between various fishing indices and (a) red hind density, and (b) red hind size. $\mathrm{r}$ is the Pearson's correlation coefficient with associated significance (p) before controlling for false discovery rate; $\mathrm{N}=19$ for all tests. ${ }^{*}$ Relationships that remained significant after controlling for false discovery rate. $\mathrm{PCA}=$ principal component analysis

\begin{tabular}{|lrc}
\hline Test & $\mathrm{r}$ & $\mathrm{p}$ \\
\hline (a) Red hind density vs. & & \\
Observational rank & 0.28 & 0.25 \\
Mean fisher rank & 0.38 & 0.10 \\
Distance to nearest port & -0.04 & 0.88 \\
Summed distance to all ports & -0.10 & 0.70 \\
Number of boats in nearest port & -0.40 & 0.12 \\
PCA fishing effort factor & 0.15 & 0.54 \\
& & \\
(b) Red hind size vs. & & \\
Observational rank & 0.23 & 0.33 \\
Mean fisher rank & 0.55 & $0.01^{*}$ \\
Distance to nearest port & 0.53 & $0.02^{*}$ \\
Summed distance to all ports & 0.47 & 0.04 \\
Number of boats in nearest port & -0.15 & 0.55 \\
PCA fishing effort factor & 0.52 & $0.02^{*}$
\end{tabular}




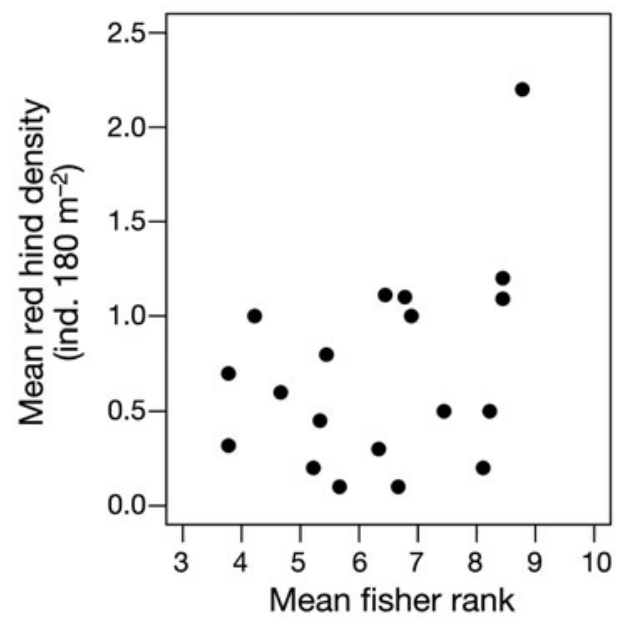

Fig. 2. Relationship between mean fisher rank of fishing intensity and mean red hind density

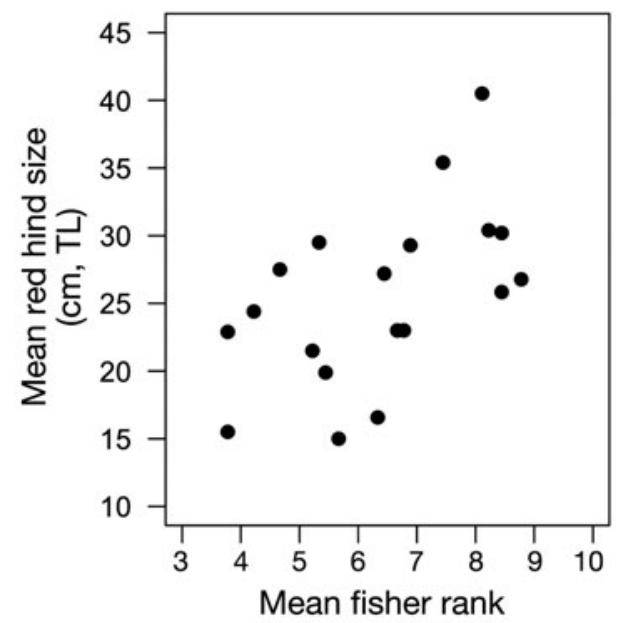

Fig. 3. Relationship between mean fisher rank of fishing intensity and mean red hind size. TL = total length

\section{DISCUSSION}

The mean densities and sizes of red hinds across 19 sites around Anguilla and neighbouring islets varied approximately 20 -fold and 3 -fold, respectively, during the non-spawning season. However, neither fish density nor body size varied with any of the highly variable habitat features that we measured. Red hind density was not related to fishing intensity but, unexpectedly, fish were larger in areas that experienced heavier fishing pressure. These results were not anticipated, and lead to a consideration of interactions between fisher behaviour and responses of target stocks.

The lack of significant relationships between any measured habitat feature and red hind body size or density is surprising because red hinds have been shown to have specific habitat associations during the non-spawning season (Burnett-Herkes 1975, Sluka et al. 1998, Sluka et al. 2001). In the Florida Keys, for example, red hinds are most abundant in low-relief habitats (Sluka et al. 1998); in the Bahamas they prefer windward hard-bottom reefs (Sluka et al. 1996). We may have overlooked a critical habitat feature preferred by red hinds around Anguilla. Alternatively, prey availability and/or fishing pressure could determine densities of red hinds. Red hinds rely heavily on small fish and crustaceans (Burnett-Herkes 1975). We were unable to quantify the abundance of these prey, but could estimate fishing pressure and thus examine the effects of exploitation on red hind populations.

We found no link between red hind density and fishing effort. The nature of such a relationship can be expected to vary. A positive relationship could arise, particularly in a young fishery, if fish density drives the distribution of fishers (Sutherland 1996, Swain \& Wade 2003, Beecham \& Engelhard 2007) or, later, if a species benefits from the removal of a competitor or predator targeted by the fishery (Jennings et al. 2001, Pinnegar et al. 2002, Dulvy et al. 2004). A negative relationship could occur when intense fishing severely depletes local populations. Both relationships could persist in large-scale, e.g. inter-island, comparisons where fisher movement among sites is limited, but should be more fleeting when fishers can redistribute their effort across sites, as in Anguilla. With hindsight, it seems possible that because of fisher mobility, a lack of relationship between red hind density and fishing effort in Anguilla may have been the most likely outcome. Our result may therefore be explained in 2 ways. Anguillian fishers may truly set their traps randomly with respect to red hind density, which may lead to depletion of some populations that are exploited too heavily. Alternatively, Anguillian fishers target disproportionately sites with high abundances of red hinds, and either they deplete these sites and move on, or such sites are highly productive and sustain catches (e.g. Wynne \& Côté 2007). A relationship between fishing effort and red hind density could have been masked if our surveys had been performed following a recruitment pulse. However, this would have generated a negative relationship between density and size, which was not the case. The effects of fishing on densities of non-spawning red hinds could also be masked by fishing effects on their spawning aggregations, for which we could not control. Lastly, red hinds may learn to avoid traps (Gilbert et al. 2001) or move to areas or depths that are less intensively fished (Tyler et al. 2009) thus disrupting any relationship between fishing effort and density.

Circumstantial evidence supports a scenario in which fishing depletes areas and fishers move among 
sites. Some $90 \%$ of Anguilla's reefs are threatened by overfishing (Pinnegar et al. 2002), which typically affects species at higher trophic levels (Pauly et al. 1998), such as red hinds. Although there is no longterm information on red hind catch-per-unit-effort, calculations from market-derived data collected during the present study are suggestive. Over $7 \mathrm{~d}$ spent at the largest fish market on the island during the nonspawning season (between August and November 2003), we measured 392 trap-caught red hinds. We estimated that this was approximately 50 to $75 \%$ of all the red hinds that passed through the market on those days but it ignores those taken by other sectors of the fishery. If we assume that the trap fishery cannot operate from November to March due to rough seas associated with passing hurricanes and seasonal ground swells, the 392 measured fish alone represent a weekly depletion of $0.1 \mathrm{~km}^{2}$ of reefs, given the average red hind density on Anguillian reefs (0.004 fish $\mathrm{m}^{-2}$ ). Over the course of a year, this extrapolates to at least $20 \%$ of the reef area of Anguilla (approximately $50 \mathrm{~km}^{2}$, Spalding et al. 2001). Therefore, although we could detect no spatial relationship between red hind density and fishing effort, exploitation may have a temporal effect on red hind densities around Anguilla. Indeed, since the completion of our fieldwork, Anguillian trap fishers have shifted their effort to target reef systems further offshore than we surveyed, probably because inshore sites have become overfished (S. Wynne pers. comm.).

Red hind size was greatest at sites where we observed more fishing activity, at sites that fishers believed were more heavily targeted, and sites furthest from port. Fishing usually affects size negatively (e.g. Dulvy et al. 2004). Indeed, the size but not density of spotted spiny lobster Panulirus guttatus around Anguilla decreased with increasing fishing effort (Wynne \& Côté 2007). In addition to being caught in traps, these lobsters are fished by hand in a highly size-selective manner (Wynne \& Côté 2007). Although fish traps are comparatively size-unselective (Hawkins et al. 2007), even unselective mortality will reduce mean age, and thus size of individuals. Thus, a positive relationship between size and fishing effort is still puzzling. We can offer several highly speculative, nonmutually exclusive explanations. First, on heavily fished reefs, red hinds may be particularly trap-shy (or experienced) and evade capture long enough to reach large sizes. Second, fishing may reduce competition among surviving fish, thereby promoting increased growth rates. Third, fishers may target sites with large groupers, but not strongly enough to reduce mean size sufficiently to disrupt the positive relationship between effort and size. Lastly, fishers may have previously targeted sites closest to shore, depleting them of large individuals before moving to sites further offshore that still have large individuals, which is when we performed our survey. This would account for the positive relationships between red hind size, distance from shore and observational/mean fisher rank, and would explain the observation that fishers now target sites further offshore than those in our survey. If so, red hind sizes on the sites that we surveyed furthest from port should have declined since our surveys.

Among groupers, size often increases with depth (e.g. Shapiro et al. 1994, Brulé et al. 1999, Wyanski et al. 2000, Sabetian 2003, La Mesa et al. 2006). There was no such relationship across the depths that we studied (Wilcoxon sign-rank test of 8 sites with data at depths of $5 \mathrm{~m}$ and $10 \mathrm{~m}: W=6, \mathrm{p}=0.11$ ), but it is conceivable that such segregation occurs over wider depth ranges. As in many sex-changing groupers, male red hinds tend to be larger than females. Therefore, size-related depth segregation implies sex-related depth segregation. Therefore, in shallow-water fisheries, such as those in Anguilla, females may be disproportionately killed. This contrasts to the assumptions of models of fishing on sex-changers, which typically simulate fisheries that select large individuals (Bannerot et al. 1987, Huntsman \& Schaaf 1994, Alonzo \& Mangel 2004, Molloy et al. 2007). Such models predict that female-first sexchangers may become sperm limited if sex ratios are skewed by the disproportionate mortality of males. However, the effects of a fishery that targets intermediately sized sex-changers are unknown.

In summary, we did not find clear evidence of an effect of fishing on non-spawning red hind populations in Anguilla. This result could imply a sustainable level of fishing on red hinds around Anguilla. However, to draw such a conclusion before ruling out other possible explanations would be unwise. Indeed, the temporal effects of overfishing may be difficult to detect in intraisland studies where fishers can adjust their spatial distribution in relation to the profitability of different sites. Our data point towards the importance of instigating a monitoring system in Anguilla to unveil shifts in the demographics of red hinds and other important species. Preliminary data collected at a major fish market suggest that large numbers of red hinds are caught during the non-spawning season and recent observations suggest that most fishers have since abandoned many of our study sites. Mortality imposed on red hinds away from spawning aggregations may therefore be significant but difficult to detect in the absence of long-term data. Yet a direct comparison of total fishing mortality during the non-spawning season to that during the reproductive season has never been performed for red hinds or any other aggregation-spawning grouper. We hope that the present study may trigger such a comparison. 
Acknowledgements. This project was supported in part by a Biotechnology and Biological Sciences Research Council studentship \# 02/A1/S/08113 to P.P.M. and the John and Pamela Salter Charitable Trust. We thank C. Payne, M. Fish, J. McWilliams and Anguillian Divers for field support, and the fishers and Government of Anguilla for logistical support and information. We also thank M. Fish for assistance in the production of Fig. 1 and S. Wynne for field support and insightful comments. We thank 3 anonymous reviewers and C. Birkeland for helpful comments on early versions of the manuscript.

\section{LITERATURE CITED}

Abernethy K (2005) Why do fishers fish where they fish? Using the ideal free distribution to identify low-conflict marine protected areas. MSc thesis, University of East Anglia, Norwich

Abernethy KE, Allison EH, Molloy PP, Cote IM (2007) Why do fishers fish where they fish? Using the ideal free distribution to understand the behaviour of artisanal reef fishers. Can J Fish Aquat Sci 64:1595-1604

Alonzo SH, Mangel M (2004) The effects of size-selective fisheries on the stock dynamics of and sperm limitation in sexchanging fish. Fish Bull (Wash DC) 102:1-13

Arreguín-Sánchez F, Pitcher TJ (1999) Catchability estimates and their application to the red grouper (Epinephelus morio) fishery of the Campeche Bank, Mexico. Fish Bull (Wash DC) 97:746-757

Ault JS, Bohnsack JA, Smith SG, Luo JG (2005) Towards sustainable multispecies fisheries in the Florida, USA, coral reef ecosystem. Bull Mar Sci 76:595-622

Bannerot S, Fox WWJ, Powers JE (1987) Reproductive strategies and the management of snappers and groupers in the Gulf of Mexico and Caribbean. In: Polovina JJ, Ralston S (eds) Tropical snappers and groupers: biology and fisheries management. Westview Press, Boulder, CO, p 561-604

Beecham JA, Engelhard GH (2007) Ideal free distribution or dynamic game? An agent-based simulation study of trawling strategies with varying information. Physica A 384: 628-646

Beets J, Friedlander A (1999) Evaluation of a conservation strategy: a spawning aggregation closure for red hind, Epinephelus guttatus, in the U.S. Virgin Islands. Environ Biol Fishes 55:91-98

Begon M, Harper JL, Townsend CR (1996) Ecology. Individuals, populations and communities, 3rd edn. Blackwell Science, Oxford

Bell JD, Craik GJS, Pollard DA, Russell BC (1985) Estimating length frequency distributions of large reef fish underwater. Coral Reefs 4:41-44

Benjamini Y, Hochberg Y (1995) Controlling the false discovery rate: a practical and powerful approach to multiple testing. J R Stat Soc B 57:289-300

Bolden SK (2000) Long-distance movement of a Nassau grouper (Epinephelus striatus) to a spawning aggregation in central Bahamas. Fish Bull (Wash DC) 98:642-645

Brulé T, Déniel C, Colás-Marrufo T, Sánchez-Crespo M (1999) Red grouper reproduction in the southern Gulf of Mexico. Trans Am Fish Soc 128:385-402

Burnett-Herkes J (1975) Contribution to the biology of the red hind, Epinephelus guttatus, a commercially important serranid fish from the tropical western Atlantic. PhD thesis, University of Miami

Cabrera JL, Defeo O (2001) Daily bioeconomic analysis in a multispecific artisanal fishery in Yucatan, Mexico. Aquat Living Resour 14:19-28

Chiappone M, Sluka R, Sealey KS (2000) Groupers (Pisces: Serranidae) in fished and protected areas of Florida, Bahamas and northern Caribbean. Mar Ecol Prog Ser 198:261-272

Christensen V, Guénette S, Heymans JJ, Walters CJ, Watson R, Zeller D, Pauly D (2003) Hundred-year decline of North Atlantic predatory fishes. Fish Fish 4:1-24

Claydon J (2004) Spawning aggregations of coral reef fishes: characteristics, hypotheses, threats and management. Oceanogr Mar Biol Annu Rev 42:265-302

> Coleman FC, Koenig CC, Collins LA (1996) Reproductive styles of shallow-water groupers (Pisces: Serranidae) in the eastern Gulf of Mexico and the consequences of fishing spawning aggregations. Environ Biol Fishes 47: 129-141

Coleman FC, Koenig CC, Eklund A, Grimes CB (1999) Management and conservation of temperate reef fishes in the grouper-snapper complex of the southeastern United States. Am Fish Soc Symp 23:233-242

Coleman FC, Koenig CC, Huntsman GR, Musick JA and others (2000) Long-lived reef fishes: the grouper-snapper complex. Fisheries 25:14-20

Colin PL, Shapiro DY, Weiler D (1987) Aspects of the reproduction of 2 groupers, Epinephelus guttatus and E. striatus in the West-Indies. Bull Mar Sci 40:220-230

Côté IM (2003) Knowledge of reproductive behavior contributes to conservation programs. In: Festa-Bianchet $M$, Apollonio M (eds) Animal behavior and wildlife conservation. Island Press, Washington, DC, p 77-92

> Defeo O, Castilla JC (1998) Harvesting and economic patterns in the artisanal Octopus mimus (Cephalopoda) fishery in a northern Chile cove. Fish Res 38:121-130

Domeier ML, Colin PL (1997) Tropical reef fish spawning aggregations: defined and reviewed. Bull Mar Sci 60: $698-726$

Domeier ML, Colin PL, Donaldson TJ, Heyman WD and others (2002) Transforming coral reef conservation: reef fish spawning aggregations component. The Nature Conservancy and Conservation International, Hawaii

Dulvy NK, Polunin NVC, Mill AC, Graham NAJ (2004) Size structural change in lightly exploited coral reef fish communities: evidence for weak indirect effects. Can J Fish Aquat Sci 61:466-475

- Ehrhardt NM, Deleveaux VKW (2007) The Bahamas' Nassau grouper (Epinephelus striatus) fishery - two assessment methods applied to a data-deficient coastal population. Fish Res 87:17-27

English S, Wilkinson C, Baker V (1997) Survey manual for tropical marine resources, 2nd edn. Australian Institute of Marine Science, Townsville

- Friedlander A, Parrish JD (1998) Habitat characteristics affecting fish assemblages on a Hawaiian coral reef. J Exp Mar Biol Ecol 224:1-30

Froese R, Pauly D (2009) Fishbase. www.fishbase.com. Accessed: July 2009

Garciá LV (2004) Escaping the Bonferonni iron claw in ecological studies. Oikos 105:657-663

Gilbert DJ, McKenzie JR, Davies NM (2001) Evidence from tag recapture experiments that fish learn to avoid fishing gear. J Agric Biol Environ Stat 6:281-291

Government of Anguilla (2000) Revised Regulations of Anguilla: F40-1. Fisheries Protection Regulations 15:3

Hawkins JP, Roberts CM (2004) Effects of artisanal fishing on Caribbean coral reefs. Conserv Biol 18:215-226

Hawkins JP, Roberts CM, Gell FR, Dytham C (2007) Effects of 
trap fishing on reef fish communities. Aquat Conserv: Mar Freshw Ecosyst 17:111-132

Heemstra PC, Randall JE (1993) Groupers of the world (Family Serranidae, Subfamily Epinephelinae). An annotated and illustrated catalogue of the grouper, rockcod, hind, coral grouper and lyretail species known to date. Report no. 0014-5602. Food and Agriculture Organization of the United Nations, Rome

Huntsman GR, Schaaf WE (1994) Simulation of the impact of fishing on reproduction of a protogynous grouper, the Graysby. N Am J Fish Manage 14:41-52

Huntsman GR, Potts J, Mays RW, Vaughan D (1999) Groupers (Serranidae, Epinephelinae): endangered apex predators of reef communities. Am Fish Soc Symp 23:217-231

Jackson JBC (1997) Reefs since Columbus. Coral Reefs 16: S23-S32

Jackson JBC, Kirby MX, Berger WH, Bjorndal KA and others (2001) Historical overfishing and the recent collapse of coastal ecosystems. Science 293:629-638

Jennings S, Kaiser MJ, Reynolds JD (2001) Marine fisheries ecology. Blackwell Sciences, Oxford

La Mesa G, Di Muccio S, Vacchi M (2006) Abundance, size distribution and habitat preferences in the grouper assemblage of the Ustica marine reserve (SW Mediterranean). Cybium 30:365-377

Mahon R, Hunte W (2001) Trap mesh selectivity and the management of reef fishes. Fish Fish 2:356-375

McGovern JC, Collins MR, Pashuk O, Meister HS (2002) Temporal and spatial differences in life history parameters of black sea bass in the southeastern United States. N Am J Fish Manage 22:1151-1163

Molloy PP, Goodwin NB, Cote IM, Gage MJG, Reynolds JD (2007) Predicting the effects of exploitation on male-first sex-changing fish. Anim Conserv 10:30-38

Murray PA, Nichols KE, Chase VM, Hodge R (2001) Logical framework analysis as a tool for management of a tropical fishery. Proc Gulf Caribb Fish Inst 52:258-270

Nagelkerken WP (1979) Biology of the graysby, Epinephelus cruentatus, of the coral reef of Curaçao. Stud Fauna Curaçao 60:1-118

Nagelkerken WP (1982) Distribution of the groupers and snappers of the Netherlands Antilles. Proc 4th Int Coral Reef Symp, Manila 2:479-484

Nemeth RS (2005) Population characteristics of a recovering US Virgin Islands red hind spawning aggregation following protection. Mar Ecol Prog Ser 286:81-97

Nemeth RS, Blondeau J, Herzlieb S, Kadison E (2007) Spatial and temporal patterns of movement and migration at spawning aggregations of red hind, Epinephelus guttatus, in the US Virgin Islands. Environ Biol Fishes 78:365-381

Pauly D, Christensen V, Dalsgaard J, Froese R, Torres F (1998) Fishing down marine food webs. Science 279: 860-863

Pauly D, Palomares ML, Froese R, Sa-a P, Vakily M, Preikshot D, Wallace S (2001) Fishing down Canadian aquatic food webs. Can J Fish Aquat Sci 58:51-62

Pinnegar JK, Jennings S, O'Brien CM, Polunin NVC (2002) Long-term changes in the trophic level of the Celtic Sea fish community and fish market price distribution. J Appl Ecol 39:377-390

Porch CE, Eklund AM, Scott GP (2006) A catch-free stock assessment model with application to goliath grouper (Epinephelus itajara) off southern Florida. Fish Bull (Wash DC) 104:89-101

Precht WF, Aronson RB (2006) Death and resurrection of Caribbean coral reefs: a palaeoecological perspective. In: Côté IM, Reynolds JD (eds) Coral reef conservation. Cam- bridge University Press, Cambridge, p 40-77

R Development Core Team (2009) R: a language and environment for statistical computing. R Foundation for Statistical Computing, Vienna

Rueda M, Defeo O (2003) A bioeconomic multispecies analysis of an estuarine small-scale fishery: spatial structure of biovalue. ICES J Mar Sci 60:721-732

Sabetian A (2003) The association of physical and environmental factors with abundance and distribution patterns of groupers around Kolombangara Island, Solomon Islands. Environ Biol Fishes 68:93-99

Sadovy Y, Domeier M (2005) Are aggregation-fisheries sustainable? Reef fish fisheries as a case study. Coral Reefs 24:254-262

Sadovy Y, Rosario A, Román A (1994) Reproduction in an aggregating grouper, the red hind, Epinephelus guttatus. Environ Biol Fishes 41:269-286

Sala E, Ballesteros E, Starr RM (2001) Rapid decline of Nassau grouper spawning aggregations in Belize: fishery management and conservation needs. Fisheries 26:23-30

Shapiro DY, Sadovy Y, McGehee MA (1993) Periodicity of sex change and reproduction in the red hind, Epinephelus guttatus, a protogynous grouper. Bull Mar Sci 53: 1151-1162

Shapiro DY, Garcia-Moliner G, Sadovy Y (1994) Social system of an inshore stock of the red hind grouper, Epinephelus guttatus (Pisces: Serranidae). Environ Biol Fishes 41: 415-422

Sluka JP, Chiappone M, Sullivan KM (1996) Habitat preference of groupers in the Exuma Cays. Bahamas J Sci 4:8-14

Sluka R, Chiappone M, Sullivan KM, Potts TA, Levy JM, Schmitt EF, Meester G (1998) Density, species and size distribution of groupers (Serranidae) in three habitats at Elbow Reef, Florida Keys. Bull Mar Sci 62:219-228

Sluka R, Chiappone M, Sullivan Sealey KM (2001) Influence of habitat on grouper abundance in the Florida Keys, U.S.A. J Fish Biol 58:682-700

Spalding MD, Ravilious C, Green EP (2001) World atlas of coral reefs. University of California Press, Berkeley

Sullivan CV, Sluka R (1996) The ecology of shallow-water groupers (Pisces: Serranidae) in the Upper Florida Keys, USA [La exologia de meros de baja profundidad (Pisces: Serranidae) en los Cayos Superiores de Florida, USA]. In: Arreguíra-Sánchez F, Munro JL, Balgos MC, Pauly D (eds) Biology, fisheries and culture of tropical groupers and snappers. ICLARM Conf Proc. ICLARM, Campeche, Mexico, 26-29 October 1993, p 74-84

Sutherland WJ (1996) From individual behaviour to population ecology. Oxford University Press, London

Swain DP, Wade EJ (2003) Spatial distribution of catch and effort in a fishery for snow crab (Chionoecetes opilio): tests of predictions of the ideal free distribution. Can J Fish Aquat Sci 60:897-909

Tyler EHM, Speight MR, Henderson P, Manica A (2009) Evidence for a depth refuge effect in artisanal coral reef fisheries. Biol Conserv 142:652-667

Vincent ACJ, Sadovy Y (1998) Reproductive ecology and the conservation and management of fishes. In: Caro TM (ed) Behavioral ecology and conservation biology. Oxford University Press, Oxford, p 209-245

Wyanski DM, White DB, Barans CA (2000) Growth, population age structure and aspects of the reproductive biology of snowy grouper, Epinephelus niveatus, off North Carolina and South Carolina. Fish Bull (Wash DC) 98:199-218

Wynne SP, Côté IM (2007) Effects of habitat quality and fishing on Caribbean spotted spiny lobster populations. J Appl Ecol 44:488-494 